\title{
The copy quantities of TRECs as a biomarker for screening SCID in newborns $\triangle a$ meta-analysis
}

\section{Bihan Li}

Jilin University

\section{Zhiyong Sun}

Jilin Women and Children's Health Hospital

\section{Ying Liu}

Jilin Women and Children's Health Hospital

Jinxia Song

Yan bian maternal and child health care hospital

\section{Lijuan Wang}

Wangqing maternal and child health and family planning service center

\section{Gaokai Li}

Jilin University

Ying Liu

Jilin University

Shilong Sun ( $\nabla$ slsun@jlu.edu.cn )

Jilin University https://orcid.org/0000-0003-2911-9681

\section{Research Article}

Keywords: Severe combined immunodeficiency (SCID), newborn screening (NBS), T-cell receptor excision circles (TRECs), Meta-analysis

Posted Date: November 8th, 2021

DOI: https://doi.org/10.21203/rs.3.rs-985374/v1

License: @ (i) This work is licensed under a Creative Commons Attribution 4.0 International License. Read Full License 


\section{Abstract \\ Purpose}

Severe combined immunodeficiency (SCID) threatens the newborns' living qualities. The aim of our study is to evaluate the the value of detecting the copy quantities of T-cell receptor excision circles (TRECs) in screening for the newborns' SCID.

\section{Methods}

We searched eligible studies in PubMed, Web of science, EMBASE, the Cochrane Library, China National Knowledge Infrastructure (CNKI) and chose the Endnote software to filter the whole studies. Meta-analysis was conducted with metadisc 1.4 and STATA 12.0 software. We used sensitivity and false positive rate (FPR) to evaluate this detecting method; subgroup analysis to explore the sources of heterogeneity. The literature quality was assessed by the quality assessment of diagnostic accuracy studies (QUADAS-邓).

\section{Results}

Fifteen studies were enrolled containing 3,570 cases in the decreased TREC copy quantities group and 12,186,899 cases in control group. All the included studies are of high quality. The heterogeneity in Diagnostic Odds Ratio (DOR) is $77.9 \%$. The summarized estimates revealed that the pooled sensitivity is $100 \%$ (95\% confidence interval $(\mathrm{Cl}): 99-100 \%)$, the false positive rate is 0.00 (95\% Cl: $0.00-0.00)$ and Positive Predict Value (PPV) is 0.14 (95\% Cl: 0.08-0.19). The current evidence shows detecting the copy quantities of TRECs has the screening value with a high sensitivity and positive likelihood ratio $(\mathrm{LR}+)$ for newborns' SCID without published bias $(p>0.05)$. Our result suggests 90 and 40 copies/ul of TRECs as the primary and secondary cut-off value.

\section{Conclusion}

Detecting the individual TREC contents could be used as the premise to diagnosis the newborns' SCID.

\section{Introduction}

Severe combined immunodeficiency (SCID) is a severe inherited disorder of the immune system caused by a spectrum of genetic defects. It is also the most devastating of cognate immunodeficiency which is deficit in both humoral and cellmediated immunity [1].Patients with SCID are born with profound deficiency of functional T-lymphocytes and B cells [25].Thus, newborns with SCID are susceptible to life-threatening secondary opportunistic infections, even die before the age of 1 year old [6].The overall incidence of SCID is 1:10,0000ख1:50,0000 among which $95 \%$ of the patients were males. Xlinked severe combined immunodeficiency (X-SCID)and Adenosine deaminase-deficient severe combined immune deficiency $\square$ ADA-SCID $₫$ with different mechanisms are the main forms of SCID [7-9].

T-cell receptor excision circle (TREC) $[10,11]$ is the byproduct of T-cell receptor (TCR) gene segments recombination during their maturation in the thymus to identify antigens and express a $\beta$ TCRs inherent [12-14]. TREC is generated late by $70 \%$ of all mature T cells and do not reduplicate during cell division. Consequently, the copy quantity of TRECs could be used to evaluate the T-cell developing as well as monitor immune reconstitution following hematopoietic stem cell transplantation (HSCT), curative bone marrow (BM) transplantation and anti-retroviral treatment, especially the Neonatal screening in clinical [15]. 
If the copy quantity of TRECs detected by a PCR reaction associating with the primers of the flanking joint of the TREC

circles is decreased or deleted, we may have a high degree of suspicion of SCID [6]. Subsequently, we could diagnosis SCID as well as the subtypes of SCID through evaluating the absolute lymphocyte count (ALC) on cord blood samples or detecting DNA sequence variants in clinical [16]. Early diagnosis is the key to improve the survival rate of newborns with SCID. At present, America, Netherlands, Taiwan, China has applied quantitation detection technology of TREC to neonatal screening for SCID.

The aim of this meta-analysis is to show the value of TREC copy quantities in screening for SCID in newborns. Furtherly, we could explicit its practical application value in all over the world based on big data analysis.

\section{Materials And Methods}

\section{Literature search and identification of eligible studies}

A literature search was performed for studies evaluating the value of detecting the copy quantities of TRECs for screening SCID. This study takes pre-retrieval strategy before formal retrieval strategy in the form of a combination of keywords such as "SCID," "TREC" and free words such as "Combined Immunodeficiencies, Severe," "Combined Immunodeficiency, Severe," "Immunodeficiencies, Severe Combined,"and so on. If necessary, we combine the literature retrocopied and manual retrieval. The main duration is from January, 2010 to January, 2021.

Included studies should meet all the following inclusion criteria:

(1) the paticipants are all newborns ( $\leq 28$ days) ; (2) the number of total sample, true positive value (TP), false positive value (FP), true negative value (TN) and false negative value (FN) can be obtained directly or indirectly; (3) studies evaluated TRECs based on newborn screening (NBS), detected typical SCID and (or) other T-cell lymphopenia (TCL); (4) cohort studies of which TRECs were detected in the period of newborn; (5) full text in English or Chinese available; and (4) the main research subjects are newborns regardless of race, sex, language, ethnicity, or geographic area.

We excluded the following: (1) studies with overlapping data or without usable data reported. (2) studies without qualified experimental or control group. (3) review; editorials; systematic reviews; summary of the meeting; case report and commententary or studies with duplicate publication.

All of the literatures in line with the above criteria are considered to be qualified studies.

\section{Data extraction and quality assessment}

Two reviewers extracted all the references independently according to the titles and abstracts details, and then two authors assessed the full text of remaining publications based on the inclusion and exclusion criteria. The following data were extracted from all the included studies:(1) the last name of the first author; (2) publication year; (3) study country/region; (4) cut-off value; and (5) The patient number with SCID symptom and without SCID symptom in the reduction copy quantity of TRECs group and the control group. Additionally, we calculated the sum of the above four groups. If necessary, the reviewers wrote to the corresponding authors for extra information or original data. Finally, we resolved the divergent opinions until consensus according to the third reviewer [17].

Two reviewers assessed the quality of the literature independently according to QUADAS- $\square$. This tool comprises four domains; each study is assessed in terms of risk of bias. If not harmonizing, the third reviewer intervened and discussed until agreement.

\section{Statistical analysis}


We extracted data from the primary studies to obtain the four cell values of a screening $2 \times 2$ table to calculate test accuracy measures of sensitivity and FPR. We pooled the sensitivity and FPR estimates using random-effects models (REM). Chi-squared test and $P$ value was performed to deter differences between two groups. The meta-analysis was performed to estimate the pooled sensitivity, specificity, Diagnostic Odds Ratio (DOR), positive likelihood ratio (LR+), negative likelihood ratio (LR-), False Positive Rate (FPR), Positive Predictive Value (PPV) and their corresponding 95\% confidence intervals (Cls) based on the random effect model. Youden Index was used to determine the best cut-off value for newborns screening with SCID. To explore the potential factors contributing to heterogeneity, we conducted subgroup analyses based on study regions, subtypes of SCID and cut-off value. To investigate the publication bias, we used the Deck's test calculated by STATA 12.0 software. A $P$-value $<0.05$ indicates signifificant publication bias.

\section{Results}

\section{Characteristics of included studies}

We identified 528 relevant articles initially through electronic and manual searches. After excluding irrelevant or duplicate articles by screening the titles and abstracts details, 46 studies were retained for further evaluation. Another 31 articles were subsequently excluded after reading the full text, and a total of 15 studies that met the inclusion criteria of this metaanalysis were finally included (Fig. 1). Except for one study published in Chinese, the rest were all published in English. All eligible studies were published between 2012 and 2021. Totally, we included 3,570 cases in the decreased TREC copy quantities group and 12,186,899 cases in control group (Tab. 1). The participants are from either America, Europe or Asia. 
Table 1

Summary characteristics of included studies and quality evaluation in the meta-analysis

\begin{tabular}{|c|c|c|c|c|c|c|c|c|c|}
\hline \multirow[t]{2}{*}{ Study } & \multirow[t]{2}{*}{$\begin{array}{l}\text { First } \\
\text { author }\end{array}$} & \multirow[t]{2}{*}{ Year } & \multirow{2}{*}{$\begin{array}{l}\text { Country/ } \\
\text { Location }\end{array}$} & \multirow{2}{*}{$\begin{array}{l}\text { Cut-off } \\
\text { value } \\
\text { (TRECs/ul) }\end{array}$} & \multicolumn{2}{|c|}{$\begin{array}{l}\text { The experimental } \\
\text { group }\end{array}$} & \multicolumn{2}{|c|}{ The control group } & \multirow{2}{*}{$\begin{array}{l}\text { QUA- } \\
\text { DAS } \\
\text { score }\end{array}$} \\
\hline & & & & & $\begin{array}{l}\text { SCID } \\
\text { number } \\
\text { (TP) }\end{array}$ & $\begin{array}{l}\text { non- } \\
\text { SCID } \\
\text { number } \\
\text { (FP) }\end{array}$ & $\begin{array}{l}\text { SCID } \\
\text { number } \\
(\mathrm{FN})\end{array}$ & $\begin{array}{l}\text { non- } \\
\text { SCID } \\
\text { Number } \\
\text { (TN) }\end{array}$ & \\
\hline 1 & $\begin{array}{l}\text { George S. } \\
\text { Amatuni }\end{array}$ & 2019 & $\begin{array}{l}\text { Ameria/ } \\
\text { California }\end{array}$ & 300 & 50 & 163 & 0 & 3251943 & 14 \\
\hline 2 & $\begin{array}{l}\text { Ana } \\
\text { Argudo- } \\
\text { Ramírez }\end{array}$ & 2019 & Catalunya & 24 & 1 & 29 & 0 & 129585 & 13 \\
\hline 3 & $\begin{array}{l}\text { Marie A. } \\
\text { P. Audrain }\end{array}$ & 2018 & $\begin{array}{l}\text { France/ } \\
\text { Nantes }\end{array}$ & 35 & 3 & 162 & 0 & 190299 & 13 \\
\hline 4 & $\begin{array}{l}\text { Yin-Hsiu } \\
\text { Chien }\end{array}$ & 2012 & $\begin{array}{l}\text { China/ } \\
\text { Taiwan }\end{array}$ & 40 & 4 & 1 & 0 & 106277 & 14 \\
\hline 5 & $\begin{array}{l}\text { H. B. } \\
\text { Gaspar }\end{array}$ & 2014 & $\begin{array}{l}\text { Ameria/ } \\
\text { California }\end{array}$ & 15 & 20 & 29 & 0 & 993674 & 13 \\
\hline 6 & $\begin{array}{l}\text { Antonia } \\
\text { Kwan }\end{array}$ & 2015 & Navajo Nation & 33 & 4 & 576 & 0 & 5520 & 12 \\
\hline 7 & $\begin{array}{l}\text { Hsuan- } \\
\text { Chieh } \\
\text { Liao }\end{array}$ & 2018 & $\begin{array}{l}\text { China/ } \\
\text { Taiwan }\end{array}$ & 90 & 2 & 54 & 0 & 252302 & 13 \\
\hline 8 & $\begin{array}{l}\text { Andrea A. } \\
\text { Maurache }\end{array}$ & 2017 & Switzerland/Surich & 25 & 611 & 922 & 0 & 6092409 & 12 \\
\hline 9 & $\begin{array}{l}\text { Erez } \\
\text { Rechavi }\end{array}$ & 2017 & Israel & 0 & 8 & 38 & 0 & 187601 & 14 \\
\hline 10 & $\begin{array}{l}\text { William T. } \\
\text { Shearer }\end{array}$ & 2012 & $\begin{array}{l}\text { America/ } \\
\text { Texaas }\end{array}$ & 18 & 6 & 14 & 0 & 850 & 13 \\
\hline 11 & $\begin{array}{l}\text { Janne } \\
\text { Strand }\end{array}$ & 2020 & Norway & 5 & 4 & 31 & 0 & 87919 & 12 \\
\hline 12 & $\begin{array}{l}\text { Laura } \\
\text { Tagliaferri }\end{array}$ & 2017 & $\begin{array}{l}\text { Germany/ } \\
\text { Heidelberg }\end{array}$ & 0 & 8 & 62 & 0 & 5964 & 13 \\
\hline 13 & $\begin{array}{l}\text { Caroline } \\
\text { Thoma }\end{array}$ & 2012 & $\begin{array}{l}\text { France/ } \\
\text { Nantes }\end{array}$ & 34 & 3 & 162 & 0 & 190298 & 13 \\
\hline 14 & $\begin{array}{l}\text { Beth } \mathrm{H} \text {. } \\
\text { Vogel }\end{array}$ & 2014 & $\begin{array}{l}\text { America/ } \\
\text { Newyork }\end{array}$ & 200 & 4 & 527 & 0 & 484634 & 13 \\
\hline 15 & Huang & 2019 & America/Wisconsin & 18 & 5 & 67 & 0 & 207624 & 13 \\
\hline
\end{tabular}




\section{Methodological quality of selected studies}

The methodological quality of the included studies according to QUADAS- $\$ was summarized

(Tab. 1). The main QUADAS- $₫$ score of the eligible studies reflected that the included studies are all relative high quality (Fig. $2,3)$.

\section{The heterogeneity analysis}

The differences in the sensitivity and specificity may result in the threshold effect, and Spearman correlation coefficient of sensitivity and specificity is a good approach to evaluate the threshold effect. In this meta-analysis, the Spearman correlation coefficient of sensitivity and 1 -specificity was 0.99 with a $p$ value of $0.296(P>0.05)$, suggesting that there is no heterogeneity from threshold effect.

Considering substantial heterogeneity existed in specificity $(R=99.8 \%)$ and DOR $(R=77.9 \%)$, a random effect model was employed. However, no specific heterogeneity in sensitivity $\left(R^{2}=0 \%\right)$ was shown, so, we chose fixed effects model (Tab. 2$)$. The results showed that the pooled sensitivity and FPR were 1.00 (95\% Cl: $0.99-1.00)$ and 0.00 (95\% Cl: 0.00-0.00), respectively (Fig. 4, 5). The results also revealed that the combined LR+ was $1729.42(95 \% \mathrm{Cl}: 380.24-7865.84)$, indicating that newborns with reduced copy quantities of TRECs had a nearly 1800-fold higher chance of SCID compared with others without decreased copy quantities of TRECs. In respect to NLR, the pooled NLR is 0.06 (95\% Cl: 0.02-0.19) (Tab. 3). What is more, the pooled PPV is $0.14(95 \% \mathrm{Cl}: 0.08-0.19)$ which means the rate of actual SCID in newborns with decreased copy quantities of TRECs is $14 \%$ (Fig. 6).

Table 3

The sensitivity, FPR, LR(+), LR(-) of the included studies 


\begin{tabular}{|llll|}
\hline Author name & Year & $\begin{array}{l}\text { Sensitivity } \\
(95 \% \mathrm{Cl})\end{array}$ & $\begin{array}{l}\text { False-positive rate(FPR) } \\
(95 \% \mathrm{Cl})\end{array}$ \\
\hline George S. Amatuni & 2019 & $1.00(0.93-1.00)$ & $0.00(0.00-0.00)$ \\
\hline Ana Argudo-Ramírez & 2019 & $1.00(0.03-1.00)$ & $0.00(0.00-0.00)$ \\
\hline Marie A. P. Audrain & 2018 & $1.00(0.29-1.00)$ & $0.00(0.00-0.00)$ \\
\hline Yin-Hsiu Chien & 2012 & $1.00(0.40-1.00)$ & $0.00(0.00-0.00)$ \\
\hline H. B. Gaspar & 2014 & $1.00(0.83-1.00)$ & $0.00(0.00-0.00)$ \\
\hline Antonia Kwan & 2015 & $1.00(0.40-1.00)$ & $0.09(0.09-0.10)$ \\
\hline Hsuan-Chieh Liao & 2018 & $1.00(0.16-1.00)$ & $0.00(0.00-0.00)$ \\
\hline Andrea A. Maurache & 2017 & $1.00(0.99-1.00)$ & $0.00(0.00-0.00)$ \\
\hline Erez Rechavi & 2017 & $1.00(0.63-1.00)$ & $0.00(0.00-0.00)$ \\
\hline William T. Shearer & 2012 & $1.00(0.54-1.00)$ & $0.02(0.01-0.03)$ \\
\hline Janne Strand & 2020 & $1.00(0.40-1.00)$ & $0.00(0.00-0.00)$ \\
\hline Laura Tagliaferri & 2017 & $1.00(0.63-1.00)$ & $0.01(0.01-0.01)$ \\
\hline Caroline Thoma & 2019 & $1.00(0.29-1.00)$ & $0.00(0.00-0.00)$ \\
\hline Beth H. V ogel & 2014 & $1.00(0.40-1.00)$ & $0.00(0.00-0.00)$ \\
\hline Huang & 2019 & $1.00(0.48-1.00)$ & $0.00(0.00-0.00)$ \\
\hline Pooled analysis & & $1.00(0.99-1.00)$ & $0.00(0.00-0.00)$ \\
\hline (95\% Cl) & & $1729.42(380.24-7865.84)$ \\
\hline Positive likelihood ratio (LR+) & $95 \% \mathrm{Cl})$ & $0.06(0.02-0.19)$ & \\
\hline Negative likelihood ratio (LR-) $(95 \% \mathrm{Cl})$ & & & \\
\hline
\end{tabular}

\section{Subgroup analysis and optimal cut-off value for screening SCID}

In order to explain the heterogeneity, we adopted subgroup analysis based on the regions of the included studies, the types of SCID and cut-off value. However, we did not find the source of heterogeneity.

According to similar DOR, detecting copy quantities of TRECs could be used to different types of SCID. In consideration of high DOR and LR+, althought detecting copy quantities of TRECs is more suitable for Asia, it could be also used to America and Europe. Besides, based on high DOR and LR+,a cut-off value which may be $\geq 90$ copies/ul could be suitable (Tab. 3). However, according to the Youden Index, the most equitable cut off value is 40 copies/ul. So, we suggest that a cut-off value which may be just 90 copies/ul is used for primary screening, subsequently; 40 copies/ul is used for secondary screening.

\section{Publication bias analysis}

The Deck's result are $0.118(P>0.05)$ which means a low likelihood of publication bias existed in our meta-analysis.

\section{Discussion}


The main two macromolecular types of SCID are X-SCID and ADA-SCID. X-SCID is a severe immune disorder caused by mutation of the interleukin (IL)-2 receptor gamma chain gene (IL2RG) located on the X chromosome. The dysfunction of IL2 Ry chain may lead to severe T cells deficits and B cells dysfunction, and furtherly lead to the decreased copy quantity of TRECs. ADA-SCID is a rare hereditary disease affecting purine metabolism, the morbidity rate is estimated to be 1:200,000 1:1000,000, which accounts for 10-15\% of all SCID [18]. ADA-SCID differs from X-SCID which may be due to a large number of ADA gene mutations. ADA produces several kinds of costimulatory signal in different cells as associated with CD26. ADA-CD26 interaction stimulates the activation of T helper 1 (Th1) and secretion of proinflammatory cytokines IFN- $\gamma$, TNF-a, and IL-6 during T cell receptor (TCR)/ CD3 engagement [19]. The dysfunction of ADA may lead to the decrease of proinflammatory cytokines and the performance lose of Th1, and furtherly lead to the decreased copy quantity of TRECs.

For SCID, what puzzled us are the characteristics of lacking of recognizable features on physical test, non-typical symptom in early life. NBS for SCID based on measuring TREC copy quantities allows early identification, protection from infection which is characterized by simple collected and low charge. TREC is the toroidal and free DNA characterized by the nature of stable during the gene rearrangement of $T$ lymphocytes cell receptors and appears in the late differentiation of $T$ lymphocytes cells in thymus [20]. TREC could not be duplicate and could be dilute during the proliferate of T cells. TREC only exist in the aßT cells with initial phenotypes. Because more than $95 \%$ T cells in peripheral blood is a $\mathrm{\beta T}$ cells, the quantities of the TRECs in peripheral blood mononuclear cells could represent the quantities of native T cells as TCR genes rearrange initially and form functional TCR genes. Mei W. Baker reviewed that the quantity of TRECs is related to CD45RA: CD45RO ratio [21]. However, several previous studies reported that the copy quantities of TRECs in patients with CD40 ligand deficiency was identical with those with normal CD40 ligand in the cell differentiation process. So, it is unreliable to diagnosis SCID based on sole analysis CD marker [22]. Molecular TREC could be taken as one of the measurable indicators for the initial SCID screening in newborns with clinical appearance.

According to analysis of the included studies, we find TREC cut-off values varied from 24 to $300 \mathrm{copies} / \mathrm{ul}$. The mean TREC content is 53 copies/ul, and median 35 copies/ ul. The main reason of the difference might be due to the different definition method or laboratory method. In the studies (cut-off value > $100 \mathrm{copies} / \mu \mathrm{L}$ ), Beth $\mathrm{H}$. Vogel chose ten percent of the normal value or 2-3 times of the patients' value as cut-off value. Besides SCID, TREC is also the biomarker for other immunologic diseases. So, even George S. Amatuni chose the cut-off value (300 copies $/ \mu \mathrm{L}$ ) which is about determining SCID and excluding other diseases. In the studies (cut-off value $\leq 100$ copies $/ \mu \mathrm{L}$ ), the most studies chose 0.5 th or 1 st percentiles all the collected sample as the cut-off value. Ana Argudo-Ramírez and Huang chose the cut-off value based on retest rate, referral rest, missed diagnosis rate and positive detection rate. Besides, only two studies chose cut-off value according to Receiver Operating Characteristic (ROC) curve and the sudden dropped copy quantities of samples. The population and sample size also could be the reasons result in different cut-off value. Lowering the cut-off value will reduce the amount of referrals and other TCL cases and the followed pressure on the health care system without decreasing the sensitivity of NBS for SCID. However, if the cut-off value is much higher, it may have a higher FPR in premature infants. So, it is necessary to formulate an opt and consistent cut-off value according to the different regions and population [23]. To ensure a reference cut-off value, we systhesised all the included studies containing different regions and population. Finally, we recommend 90 and 40 copies/ul as the primary and secondary cut-off value, respectively [24]. What is more, we hope that this recommend reference value could be furtherly confirmed and practiced in Chinese population, even all over the world.

In terms of heterogeneity, one of the primary causes of heterogeneity in test accuracy studies is threshold effect, which is arised according to the different cut-off value to define a positive or negative test result and furtherly lead to different sensitivities and specificities. We used the Spearman correlation coefficient to analyze the threshold. The result showed $P>0.05$, indicating that there is no specific heterogeneity in the threshold. We found the detecting methods for TREC are all based on PCR analysis or TREC kit of which the essence is also PCR. However, there are no unified primers which may have different augmentational efficiency, different operational technique for PCR analysis; different sensitivity of operating machine; and inconsistent standard for systhsising standard curve. Therefore, these may all produce difference in quantifying the copy quantities of TRECs, then furtherly result in the heterogeneity. 
Actually, SCID could be cured if diagnosis early. So, seeking the pre-detecting biomarker is important to predict SCID. Besides the simple collected, taking the copy quantity as the biomarker could save the cost and furtherly reduce the economic burden of families and nation. Also, our meta-analysis systematically analyzed the relationship between the TREC copy quantity and SCID. The result showed the TREC copy quantity as a biomarker is reliable. Besides, we integrated the published data and produced this meta-analysis. The relative study has not been reported before. We also need consider some limitations in this analysis. Firstly, our meta-analysis included data from America, Europe and Asia without Australia and Africa. Also, the sample could lose to follow-up before determining whether SCID occurred or not [25]. If we own the comprehensive data contained different continents, the result will be more representative and persuasive. Secondly, we find the cut-off value is not consistent in the included studies. The different detecting assays with different clinical recognition lead to different sensitivity and specificity. The more consistent the detecting method is, the more persuasive and application prospect detecting the copy quantity of SCID is. If the consistence could be achieved, we could have fixed cut-off value and standard case definition all over the world.

In conclusion, this meta-analysis supports the notion that the TREC copy quantity could be used as an biomarker to screen for newborns' SCID. However, the data we extracted are all in developed countries apart from the underdeveloped regions. So, larger-scale studies comprising different regions and population are still necessary to confirm more practicing value about this detecting method. Besides, in terms of TREC detecting method, the Real Time PCR is the main method to detect TREC. With the development of modern technology, digital PCR is a more precise method to detect TREC copy quantity and furtherly ensure a more appropriate cut-off value.

\section{Declarations}

\section{Acknowledgments}

This work was supported by Jilin scientific and Technological Developing Scheme Project (No.20200404179YY). We would like to acknowledge Dr. Kou Changgui for his help and support with sample precessing.

Funding This study was funded by Jilin scientific and Technological Developing Scheme Project (No.20200404179YY).

Availability of data and material Data availability upon request.

Authors' contributions B.L. contributed to the conception and design the study. B.L. and Z.S. performed the systematic literature search, quality assessment, and meta-analyses. B.L. and Y.L. ${ }^{2}$ participated in the interpretation of the results. B.L. contributed to draft the initial manuscript. B.L., J.S., L.W., G.L., Y.L. ${ }^{1}$ and S.S. reviewed the manuscript. B.L. critically edited and revised the manuscript. All authors gave final approval of the version to be published and agreed to be accountable for all aspects of the work.

\section{Declarations}

Code availability Not applicable.

Ethics approval Not applicable.

Consent to participate Not applicable

Consent for publication Not applicable.

Conflict of Interest The authors declare that they have no conflict of interest.

\section{References}


1. Barreiros L A , Segundo G , Grumach A S , et al. A Novel Homozygous JAK3 Mutation Leading to T-B+NK-SCID in Two Brazilian Patients[J]. Frontiers in Pediatrics, 2018, 6:358. https://doi.org/10.3389/fped.2018.00358.

2. Huang $\mathrm{H}$. Newborn screening for severe combined immunodeficiency (SCID): a review[J]. Frontiers in Bioscience $A$ Journal \& Virtual Library, 2005, 10(1-3). https://doi.org/10.2741/1596.

3. Kwan A, Puck J M. Newborn screening for severe combined immunodeficiency in 11 screening programs in the United States. [J]. Current Pediatrics Reports, 2015, 3(1):34-42. https://doi.org/10.1001/jama.2014.9132.

4. Lev A, Simon A J, Trakhtenbrot L, et al. Characterizing T Cells in SCID Patients Presenting with Reactive or Residual T Lymphocytes[J]. Clinical \& Developmental Immunology, 2014, 2012(12):261470. https://doi.org/10.1155/2012/261470.

5. Dasouki M, Jabr A, Aldakheel G, et al. TREC and KREC profiling as a representative of thymus and bone marrow output in patients with various inborn errors of immunity[J]. Clinical \& Experimental Immunology. https://doi.org/10.1111/cei.13484.

6. Puck J M. Newborn screening for severe combined immunodeficiency and T-cell lymphopenia[J]. Immunological Reviews, 2019, 287(1):241-252. https://doi.org/10.1111/imr.12729.

7. Nochi T, Suzuki S, Ito S, et al. Elucidation of the Effects of a Current X-SCID Therapy on Intestinal Lymphoid Organogenesis Using an In Vivo Animal Model[J]. Cellular and Molecular Gastroenterology and Hepatology, 2020, 10(1). https://doi.org/10.1016/j.jcmgh.2020.01.011.

8. Kohn D B, Gaspar H B. How We Manage Adenosine Deaminase-Deficient Severe Combined Immune Deficiency (ADA SCID) [J]. Journal of Clinical Immunology, 2017, 37(4):1-6. https://doi.org/10.1007/s10875-017-0373-y.

9. Touzot F, Hacein-Bey-Abina S, Fischer A, et al. Gene therapy for inherited immunodeficiency[J]. Expert Opinion on Biological Therapy, 2014, 14(6):789. https://doi.org/ 10.1517/14712598.2014.895811.

10. Strand J, Gul K A, Erichsen H C, et al. Second-Tier Next Generation Sequencing Integrated in Nationwide Newborn Screening Provides Rapid Molecular Diagnostics of Severe Combined Immunodeficiency[J]. Frontiers in Immunology, 2020, 11:1417. https://doi.org/10.3389/fimmu.2020.01417.

11. Chitty-Lopez M, Westermann-Clark E, Dawson I, et al. Asymptomatic Infant with Atypical SCID and Novel Hypomorphic RAG Variant Identified by Newborn Screening: A Diagnostic and Treatment Dilemma[J]. Frontiers in Immunology, 2020, 11:1954. https://doi.org/10.3389/fimmu.2020.01954.

12. Mallott J, Kwan A, J Church, et al. Newborn Screening for SCID Identifies Patients with Ataxia Telangiectasia[J]. Journal of Clinical Immunology, 2013, 33(3):540-549. https://doi.org/10.1007/s10875-012-9846-1.

13. Vogel B H, Bonagura V, Weinberg G A, et al. Newborn Screening for SCID in New York State: Experience from the First Two Years[J]. other, 2014, 34(3). https://doi.org/10.1007/s10875-014-0006-7.

14. Korsunskiy I, Blyuss 0 , Gordukova $M$, et al. Expanding TREC and KREC Utility in Primary Immunodeficiency Diseases Diagnosis[J]. Frontiers in Immunology, 2020, 11. https://doi.org/10.3389/fimmu.2020.00320.

15. Kwok J , Cheung S, Ho J , et al. Establishing Simultaneous T Cell Receptor Excision Circles (TREC) and K-Deleting Recombination Excision Circles (KREC) Quantification Assays and Laboratory Reference Intervals in Healthy Individuals of Different Age Groups in Hong Kong[J]. 2020. https://doi.org/10.3389/fimmu.2020.01411.

16. Madkaikar M, Aluri J, Gupta S. Guidelines for Screening, Early Diagnosis and Management of Severe Combined Immunodeficiency (SCID) in India[J]. Indian Journal of Pediatrics, 2016, 83(5):455-462. https://doi.org/10.1007/s12098-016-2059-5.

17. Raffaella $C$, F Fang, Elizabeth $M$, et al. Cancer and suicidal ideation and behaviours: protocol for a systematic review and meta-analysis[J]. Bmj Open, 2018, 8(8): e020463-. https://doi.org/ 10.1136/bmjopen-2017-020463.

18. Bradford K L, Moretti F A, Carbonaro-Sarracino D A, et al. Adenosine Deaminase (ADA)-Deficient Severe Combined Immune Deficiency (SCID): Molecular Pathogenesis and Clinical Manifestations[J]. Journal of Clinical Immunology, 2017. https://doi.org/10.1007/s10875-017-0433-3.

Page 10/16 
19. Korsunskiy I, Blyuss O, Gordukova M, et al. Expanding TREC and KREC Utility in Primary Immunodeficiency Diseases Diagnosis[J]. Frontiers in Immunology, 2020, 11. https://doi.org/10.3389/fimmu.2020.00320.

20. Baker M W, Grossman W J, Laessig R H, et al. Development of a routine newborn screening protocol for severe combined immunodeficiency[J]. Journal of Allergy \& Clinical Immunology, 2009, 124(3):522-527. https://doi.org/10.1016/j.jaci.2009.04.007.

21. Maryam N, Leila S, Stephan B, et al. Newborn screening using TREC/KREC assay for severe $T$ and $B$ cell lymphopenia in Iran[J]. Scandinavian Journal of Immunology, 2018, 88: e12699-. https://doi.org/ 10.1111/sji.12699.

22. van der Spek J, Groenwold RH, van der Burg M, van Montfrans JM. TREC Based Newborn Screening for Severe Combined Immunodeficiency Disease: A Systematic Review. J Clin Immunol. 2015 May;35(4):416-30. https://doi.org/10.1007/s10875-015-0152-6.

23. Cavazzana M, Six E, Lagresle-Peyrou C, André-Schmutz I, Hacein-Bey-Abina S. Gene Therapy for X-Linked Severe Combined Immunodeficiency: Where Do We Stand? Hum Gene Ther. 2016 Feb;27(2):108-16. https://doi.org/10.1089/hum.2015.137.

24. Kalman L, Lindegren M L, Kobrynski L, et al. Mutations in genes required for T-cell development: IL7R, CD45, IL2RG, JAK3, RAG1, RAG2, ARTEMIS, and ADA and severe combined immunodeficiency: HuGE review[J]. Genetics in Medicine, 2004, 6(1):16-26. https://doi.org/10.1097/01.GIM.0000105752.80592.A3.

25. Park JH, Jeong GH, Lee KS, Lee KH, Suh JS, Eisenhut M, van der Vliet HJ, Kronbichler A, Stubbs B, Solmi M, Dragioti E, Koyanagi A, Shin Jl, Gamerith G. Genetic variations in MicroRNA genes and cancer risk: A field synopsis and metaanalysis. Eur J Clin Invest. 2020 Apr;50(4):e13203. https://doi.org/10.1111/eci.13203.

\section{Tables}

Due to technical limitations, Table 2 is only available as a download in the Supplemental Files section.

\section{Figures}


Articles identified through database (PubMed, Web of science, EMBASE, the Cochrane library, CNKI, WANFANG) searching: $\mathrm{n}=528$

PubMed:204; Web of science:120; EMBASE:128;

The Cochrane library:74; CNKI:2; WANFANG:0

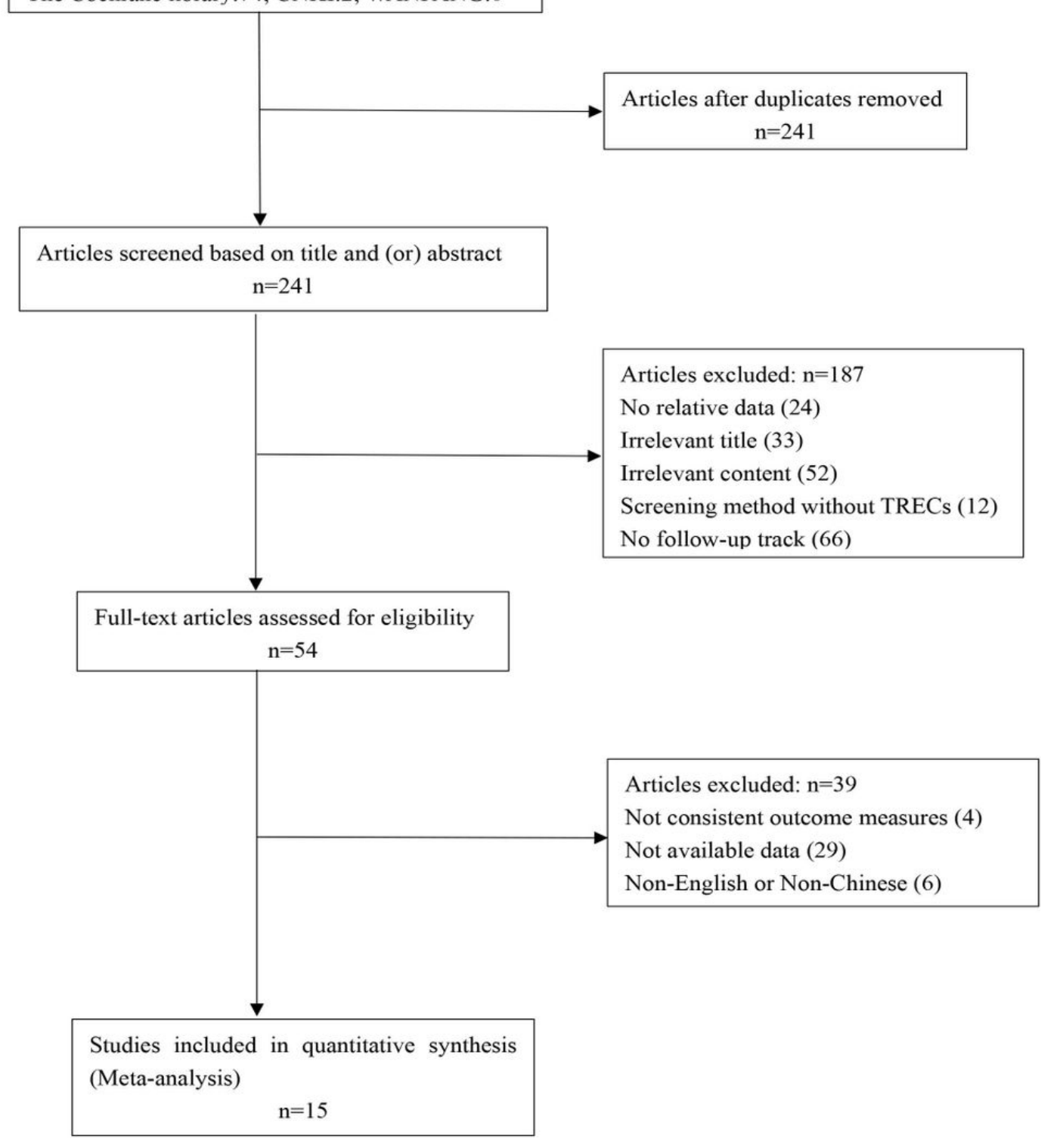

\section{Figure 1}

Flow diagram of the study selection procedures 


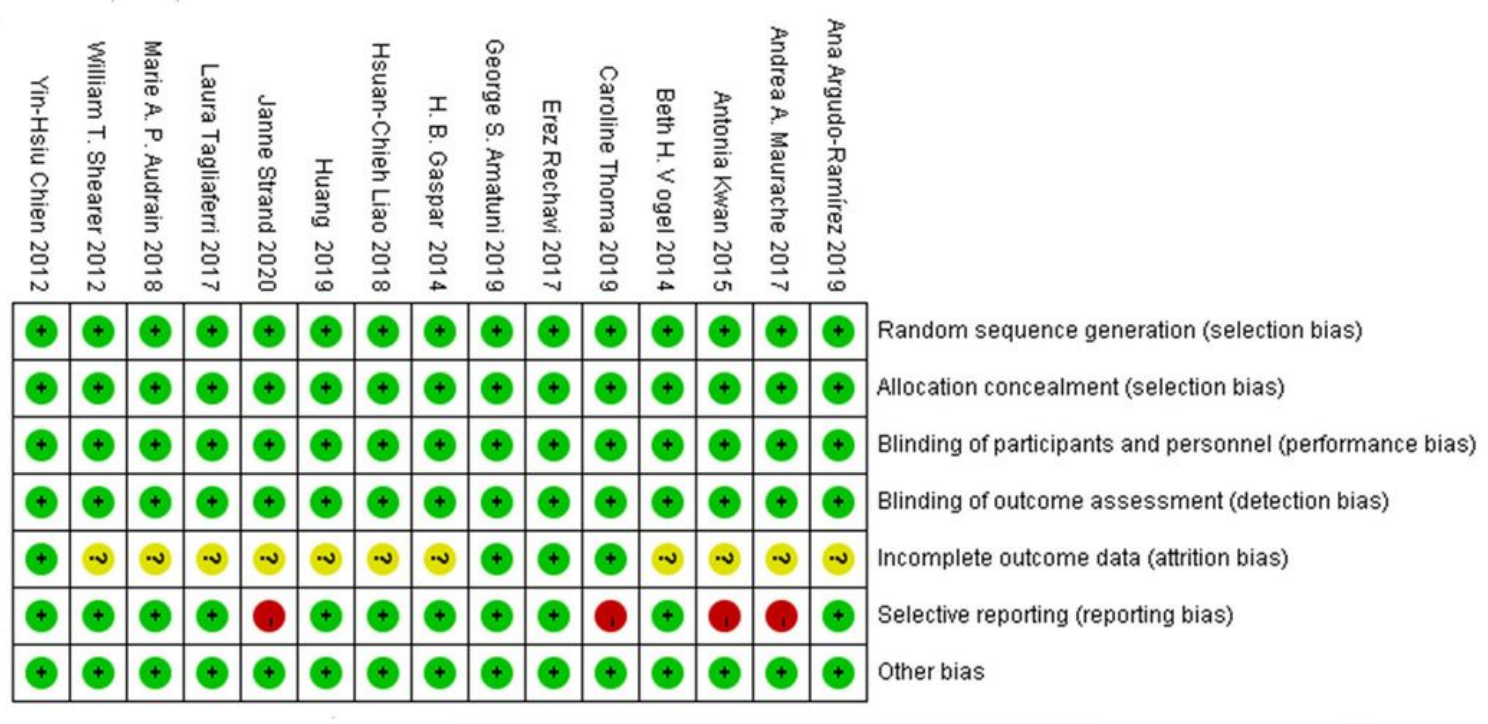

Random sequence generation (selection bias) Allocation concealment (selection bias)

Blinding of participants and personnel (performance bias)

Blinding of outcome assessment (detection bias)

Incomplete outcome data (attrition bias)

Selective reporting (reporting bias)

Other bias
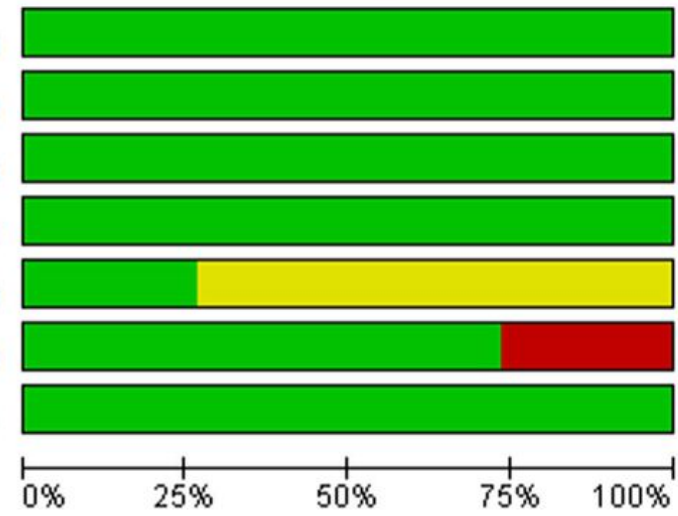

$\square$ Low risk of bias $\square$ Unclear risk of bias $\quad \square$ High risk of bias

Figure 2

Summary of the quality of included studies, using the Quality Assessment tool for Diagnostic Accuracy Studies (QUADAS- $)$ checklist 


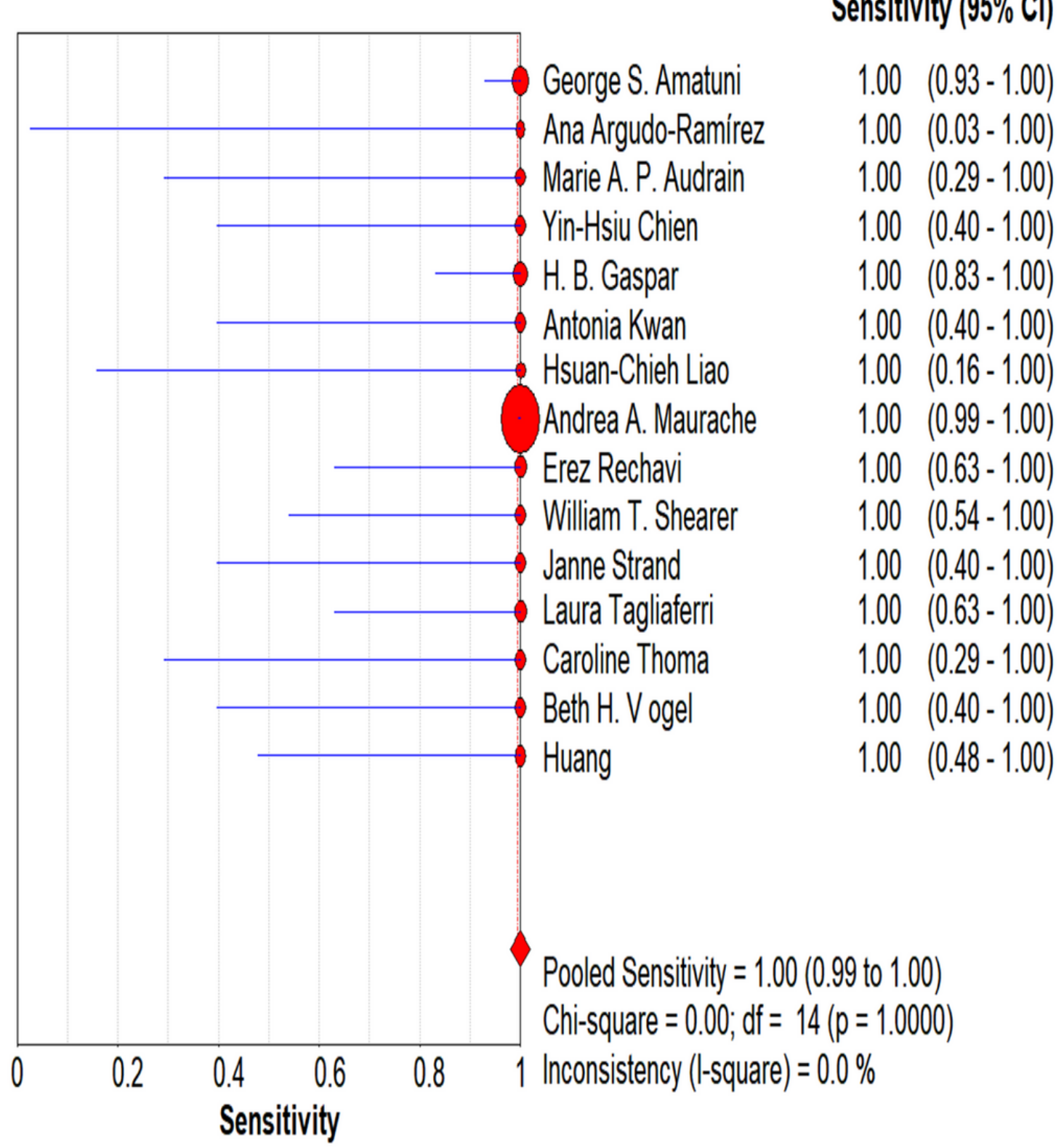

Figure 3

Forest plots of sensitivity with $95 \% \mathrm{Cl}$ and weighted pooled summary statistics using a random-effects model in assessing detecting copy quantities of TREC in screening for SCID in newborns 


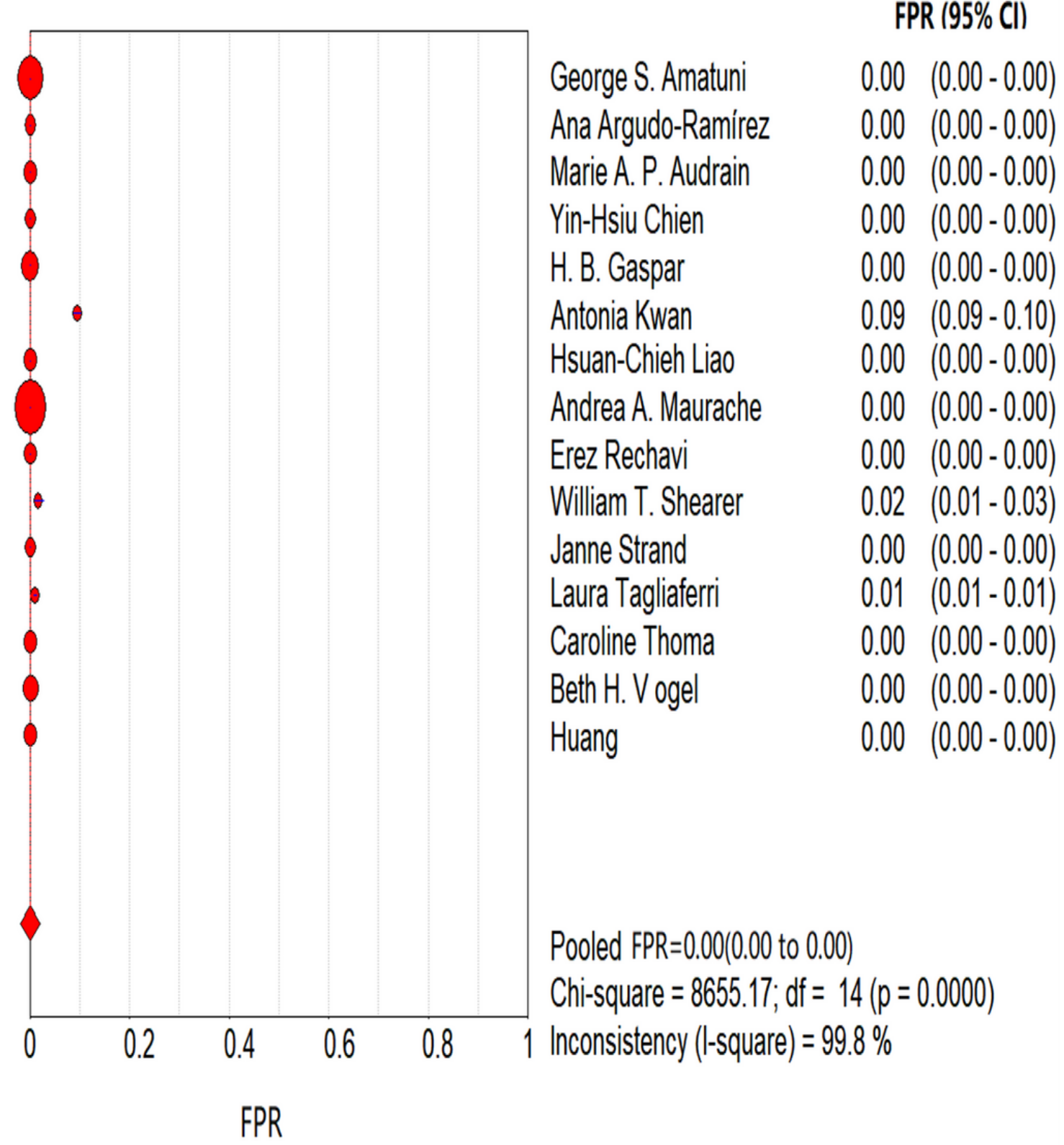

Figure 4

Forest plots of FPR with $95 \% \mathrm{Cl}$ and weighted pooled summary statistics using a random-effects model in assessing detecting copy quantities of TREC in screening for SCID in newborns 


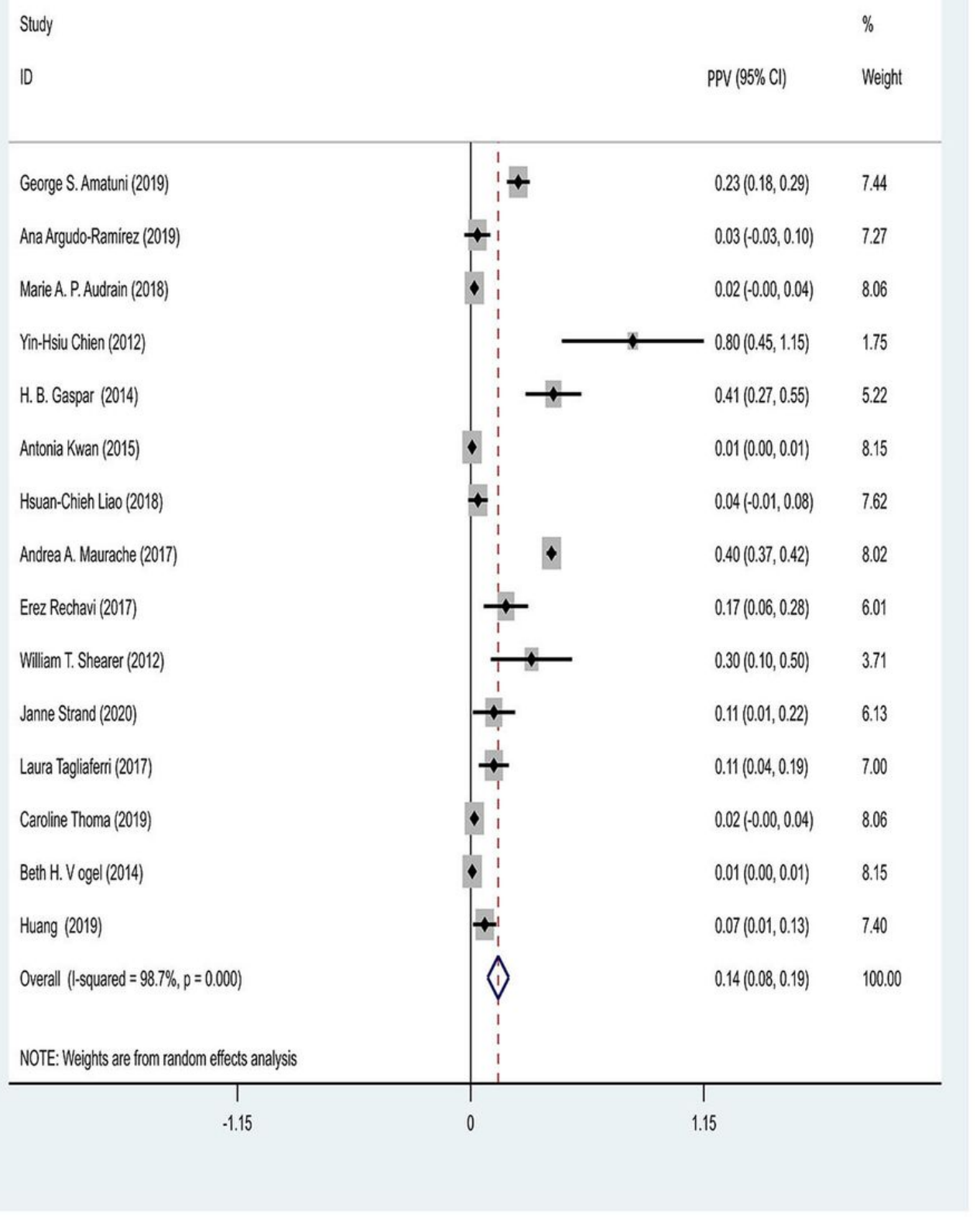

\section{Figure 5}

Forest plots of PPV with 95\% $\mathrm{Cl}$ and weighted pooled summary statistics in assessing detecting copy quantities of TREC in screening for SCID in newborns

\section{Supplementary Files}

This is a list of supplementary files associated with this preprint. Click to download.

- Table2Thesensitivity.docx 